\title{
Comparative Analysis of Semiconductor Power Losses of Galvanically Isolated Quasi-Z-Source and Full-Bridge Boost DC-DC Converters
}

\author{
Roman Kosenko (PhD student, Tallinn University of Technology/Chernihiv Nat. University of Technology), \\ Liisa Liivik (PhD student, Tallinn University of Technology), \\ Andrii Chub (Junior Researcher, Tallinn University of Technology), \\ Oleksandr Velihorskyi (Associate Professor, Chernihiv Nat. University of Technology)
}

\begin{abstract}
This paper compares semiconductor losses of the galvanically isolated quasi-Z-source converter and full-bridge boost DC-DC converter with active clamping circuit. Operation principle of both converters is described. Short design guidelines are provided as well. Results of steady state analysis are used to calculate semiconductor power losses for both converters. Analytical expressions are derived for all types of semiconductor power losses present in these converters. The theoretical results were verified by means of numerical simulation performed in the PSIM simulation software. Its add-on module "Thermal module" was used to estimate semiconductor power losses using the datasheet parameters of the selected semiconductor devices. Results of calculations and simulation study were obtained for four operating points with different input voltage and constant input current to compare performance of the converters in renewable applications, like photovoltaic, where input voltage and power can vary significantly. Power loss breakdown is detailed and its dependence on the converter output power is analyzed. Recommendations are given for the use of the converter topologies in applications with low input voltage and relatively high input current.
\end{abstract}

Keywords - DC-DC power converters; Energy efficiency; Pulse width modulation converters; Semiconductor device modeling.

\section{INTRODUCTION}

Isolated full-bridge boost (IFBB) DC-DC converters are a well known and proven topology [1]-[5]. Up to recently, its spread is limited due to the inherent drawbacks of the currentfed technology, such as high inrush current during start-up and high voltage stress of the transistors. Nevertheless, the IFBB converters can perform voltage step-up and maintain continuous input current in a wide operation range. At the same time, a new quasi-Z-Source (qZS) DC-DC converter topology has emerged that has all the benefits of the IFBB topology and does not suffer from the high inrush current, has even higher step-up factor and therefore potentially wider operation range [6]-[8], [22], [23]. Therefore, the topologies with an input stage that can work as a current-source could be preferable in such low-voltage applications as power conditioners for photovoltaic panels and fuel-cells.

Focus in this paper is on the comparison of these two topologies in terms of energy efficiency in low voltage applications. The generalized power circuit layouts of the qZS and IFBB DC-DC converters are presented in Figs. 1 and 2.

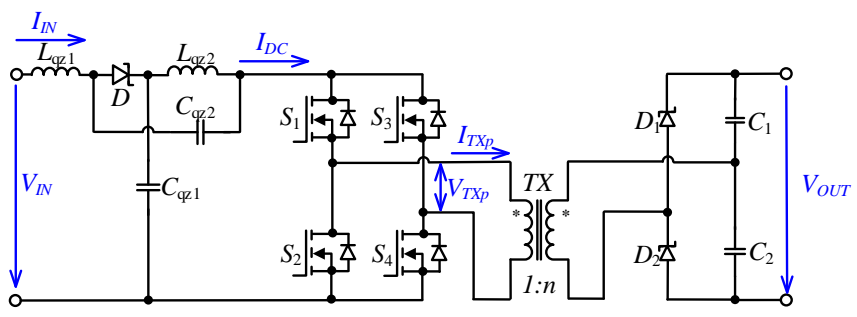

Fig. 1. Galvanically isolated qZS full-bridge DC-DC converter.

Both converters use the voltage doubler rectifier (VDR) to provide a higher voltage step-up factor and reduce the transformer turns ratio. The IFBB converter accommodates an active clamping circuit, which consists of a switch $S_{C L}$ and a capacitor $C_{C L}$ (Fig. 2). It is used to recycle the inductive energy when switching from the shoot-through to the active state, thus minimizing the turn-off losses and reducing the voltage stress of the switches.

\section{OPERATION PRINCIPLE OF THE CONVERTERS}

Fig. 3 shows the basic waveforms of the galvanically isolated qZS full-bridge DC-DC converter. The symmetric overlap of active states is used to control the converter in the continuous conduction mode (CCM). It requires generation of two control signals for the diagonal switches (one for $S_{1}, S_{4}$ and the other for $S_{2}, S_{3}$ ). These signals are of equal duration and phase-shifted by 180 degrees. The switching period consists of four time intervals:

- a) and c) are the shoot-through state intervals. All four inverter switches are conducting, qZS network inductors are accumulating energy;

- b) is an active state interval when diagonal switches $S_{1}$ and $S_{4}$ are conducting and energy is transferred to the output filter capacitor $C_{2}$;

- d) is another active state when diagonal switches $S_{2}$ and $S_{3}$ are turned on and energy is transferred to the output filter capacitor $C_{1}$.

The operation principle of the qZS DC-DC converter is detailed in [8], [9].

The waveforms of the IFBB DC-DC converter are generalized in Fig. 4. The converter has an additional switch $\left(S_{C L}\right)$, but in general the operation principle in the continuous conduction mode is similar to that of the qZS converter. 


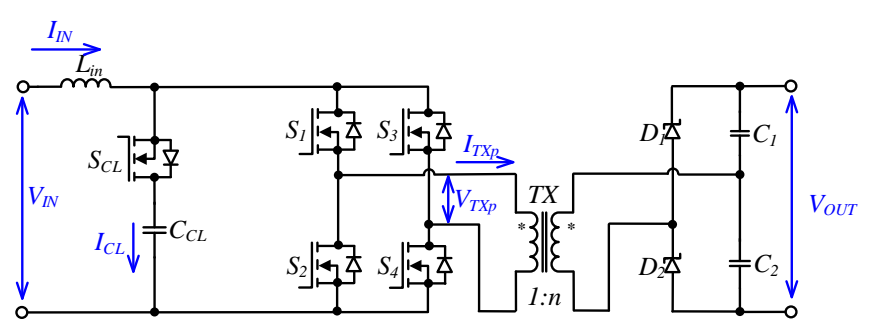

Fig. 2. Galvanically isolated full-bridge boost DC-DC converter.

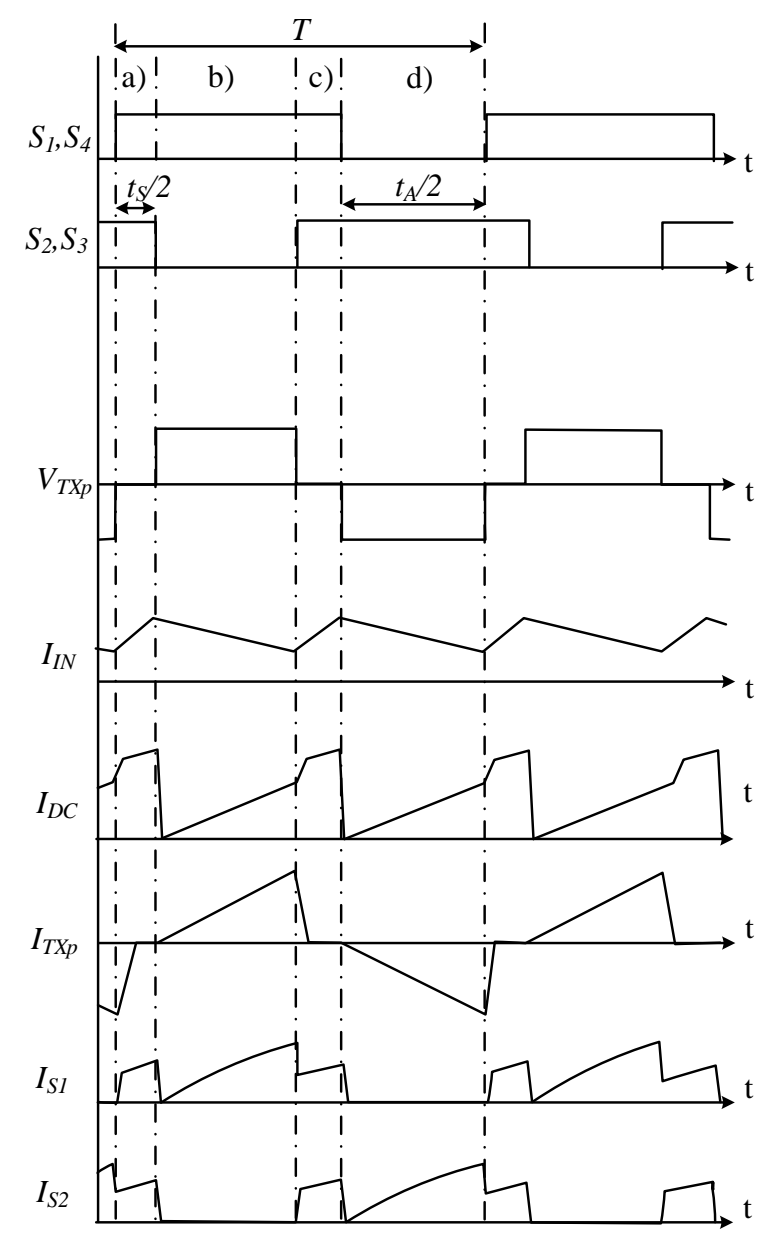

Fig. 3. Generalized waveforms of the qZS full-bridge DC-DC converter.

- a) and c) are the shoot-through intervals. All four inverter stage switches are conducting, the boost inductor $L_{I N}$ is accumulating energy, the clamping switch $S_{C L}$ is turned off;

- b) diagonal switches $S_{1}$ and $S_{4}$ are conducting, energy is transferred to the output filter capacitor $C_{2}$, the clamping switch $S_{C L}$ is turned on to protect inverter switches from the voltage overshoot during the transition from the shoot-through to the active state and back;

- d) diagonal switches $S_{2}$ and $S_{3}$ are conducting, energy is transferred to the output filter capacitor $C_{1}$, the clamping switch $S_{C L}$ is turned on to protect inverter switches from the voltage stress during the transition from the shoot-through to the active state and back.

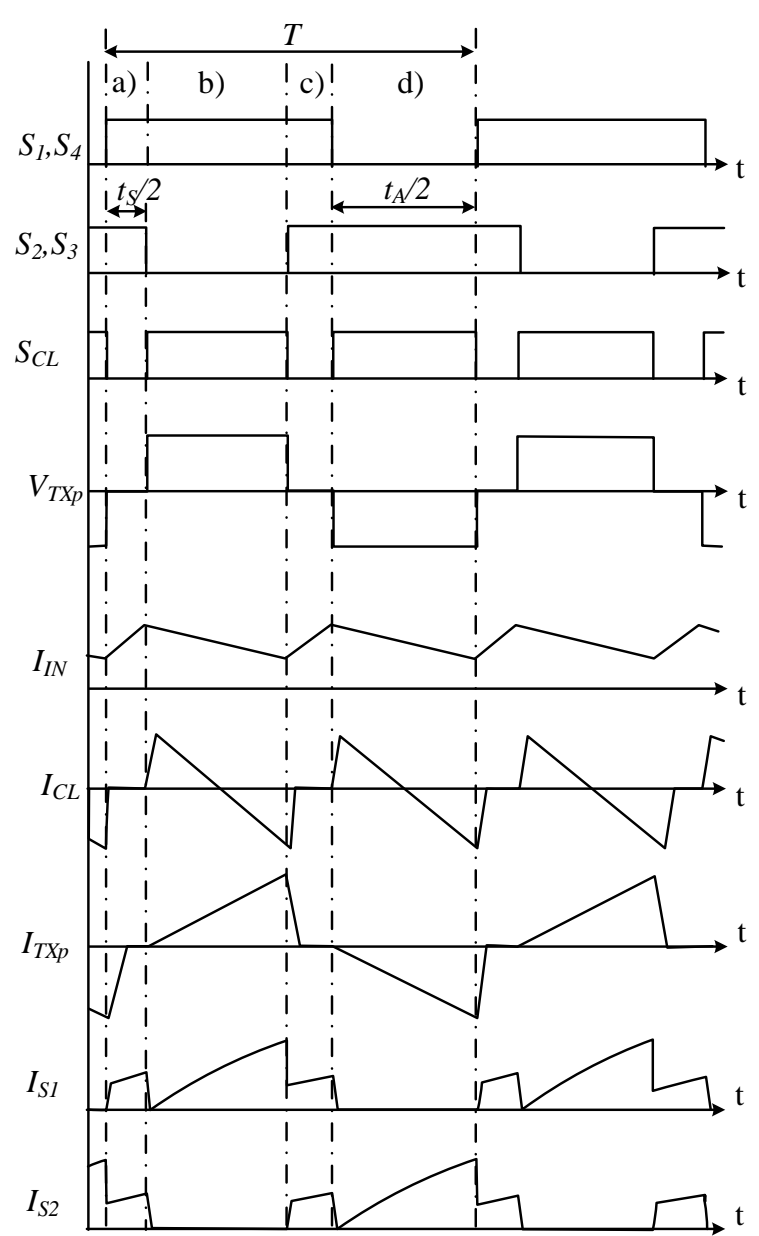

Fig. 4. Generalized waveforms of the IFBB DC-DC converter.

The operation principle of the IFBB DC-DC converter is detailed in [10], [11].

Comparison carried out in this paper is limited to the semiconductor losses because of their strong influence on the performance of both of the converters. To ensure reliable results, the converters were analyzed in the same conditions. Passive elements parameters were calculated to ensure the same input current ripple for both topologies. $L_{I N}, L_{q z 1}$ and $L_{q z 2}$ were selected to achieve peak-to-peak input current ripple at the level of $10 \%$ of the nominal current.

As seen from Figs. 3 and 4, the current through the primary transformer winding $\left(I_{T X p}\right)$ is nearly the same for both topologies. Thus, the losses in the magnetic elements have to be nearly equal for both converter topologies. They were excluded from our analysis, since the main difference in the power losses is within semiconductor losses.

\section{DESIGN CONSIDERATION}

Both of the compared topologies are boost-enabled, and their switching period $T$ consists of the shoot-through and the active state. The duty cycles of the shoot-through and the active state are interdependent, as shown in (1):

$$
\frac{t_{A}}{T}+\frac{t_{S}}{T}=D_{A}+D_{S}=1,
$$


where $t_{A}$ and $t_{S}$ are the duration of the active and the shootthrough state, correspondingly, $D_{A}$ and $D_{S}$ are the duty cycles of the active and the shoot-through state, correspondingly.

The output voltage of the qZS full-bridge converter can be expressed as

$$
V_{O U T}=2 n \cdot \frac{1}{1-2 D_{S}} \cdot V_{I N},
$$

where $n$ is the transformer turns ratio, $V_{I N}$ is the input voltage of the converter, and $V_{O U T}$ is the output voltage of the converter. For the IFBB converter, the output voltage can be calculated as

$$
V_{\text {OUT }}=2 n \cdot \frac{1}{1-D_{S}} \cdot V_{I N} .
$$

The main advantage of the discussed converters is the ability to operate with continuous input current. To maintain the CCM, the energy accumulating inductors must be selected based on the converter operation parameters.

For the IFBB converter, minimal inductance of the boost inductor required to limit the input current ripple on the level of $\Delta I \%$ can be calculated as [12]

$$
L_{i n}=\frac{V_{I N \min }^{2} \cdot D_{S \max }}{f_{S W} \cdot P \cdot \Delta I_{\%}} \cdot 100,
$$

where $f_{S W}$ is the switching frequency, $\Delta I_{\%}$ is the selected peakto-peak input current ripple, $D_{S \max }$ is the maximum shootthrough duty cycle, $P$ is the rated power of the converter, and $V_{I N \min }$ is the minimum input voltage of the converter.

The inductance of the qZS network inductors required to limit the input current ripple on the level of $\Delta I_{\%}$ from the nominal is expressed by [9]

$$
L_{q z 1}=L_{q z 2}=\frac{1-D_{S \max }}{1-2 D_{S \max }} \cdot \frac{V_{I N \min }^{2} \cdot D_{S \max }}{f_{S W} \cdot P \cdot \Delta I_{\%}} \cdot 100 .
$$

The capacitance of the capacitors in the qZS network required to limit the ripple of the DC-link voltage can be calculated as [13]:

$$
C_{q z 1}=C_{q z 2}=\frac{2 n \cdot P \cdot D_{S \max }}{V_{O U T} \cdot \Delta V_{\%} \cdot V_{I N \text { min }} \cdot f_{S W}} \cdot 100,
$$

where $\Delta V \%$ is the peak-to-peak voltage ripple of the capacitors.

To limit the output voltage ripple on the level of $\Delta V_{\%}$, the capacitance of VDR capacitors should be at least [8]:

$$
C_{1}=C_{2}=\frac{P \cdot D_{S \max }}{\Delta V_{\%} \cdot f_{S W} \cdot V_{O U T}^{2}} \cdot 100,
$$

where $V_{\text {OUT }}$ is the nominal output voltage of the converter.

The capacitance of the clamping capacitor $\left(C_{C L}\right)$ is based on the $L C$ circuit resonant frequency. The clamping capacitor $\left(C_{C L}\right)$ can resonate with either the boost inductor $\left(L_{i n}\right)$ or with the transformer leakage inductor $\left(L_{T X_{-} l e a k}\right)$. This resonant frequency should be lower than the doubled switching frequency $f_{S W}$. Since the IFBB converter circuit has two inductors, the clamping capacitance is calculated as the maximum of two values, which is usually determined by $L_{T X \_l e a k}[14]$ :

$$
C_{C L}=\frac{1}{16 \cdot L_{T X_{-} \text {leak }} \cdot f_{S W}^{2} \cdot \pi^{2}} .
$$

\section{COMPARATIVE ANALYSIS OF POWER LOSSES AND EFFICIENCY}

The semiconductor losses of the converter can be categorized to a few major types. Analytical expressions of semiconductor losses in both topologies are well described in [9], [11], [15]-[17]. Here some of the resulting expressions adapted for the discussed converters and applications are presented.

\section{A. Inverter Losses}

The primary low-voltage MOSFET semiconductor losses are calculated based on the MOSFET on-state resistance, the average input current, and transformer primary winding current averaged over on the half of the period. The use of average input current value instead of RMS value simplifies the analytical expressions for conduction losses during shootthrough state without significant impact on precision. For example, for the input current with ripple of $50 \%$ the difference between average and RMS values is around $1 \%$ only [17]. Conduction losses are different for the active and the shoot-through state as the different number of MOSFETs are conducting (Fig. 5). So the resulting equation consists of these two components. Total conduction losses in inverter MOSFETs of IFBB DC-DC converter are expressed by:

$$
\begin{aligned}
P_{M s_{-} c o n}=R_{D S(o n)} & \cdot\left(\frac{P}{V_{I N}}\right)^{2} \cdot D_{S}+ \\
+ & \cdot R_{D S(o n)} \cdot\left(\frac{4 \cdot n \cdot P}{\sqrt{3} \cdot V_{\text {OUT }}}\right)^{2}
\end{aligned}
$$

where $R_{D S(o n)}$ is the on-state resistance of the MOSFET.

Total conduction losses in inverter MOSFETs of qZS DC-DC converter are expressed by:

$$
\begin{aligned}
P_{M S_{-} c o n}=R_{D S(o n)} & \cdot\left(\frac{2 \cdot P}{V_{I N}}\right)^{2} \cdot D_{S}+ \\
+ & 2 \cdot R_{D S(\text { on })} \cdot\left(\frac{4 \cdot n \cdot P}{\sqrt{3} \cdot V_{\text {OUT }}}\right)^{2}
\end{aligned}
$$

As seen from (9) and (10) component of the inverter MOSFETs conduction losses that corresponds to the active state is the same for both topologies as the difference in RMS values of the transformer primary winding current is compensated by difference in duty cycles of the active state. At constant input current $\left(P / V_{I N}\right)$, the MOSFET current during the shoot-through state interval is two times higher in qZS converter than in IFBB converter. However, the shoot-through duty cycle $\left(D_{S}\right)$ for qZS converter is two times lower than for IFBB converter. Therefore component of the inverter 


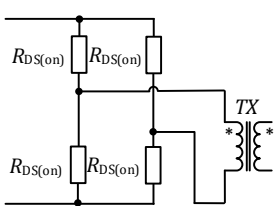

a)

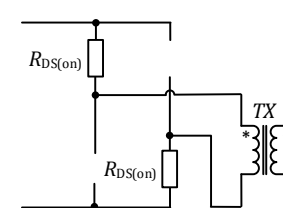

b)

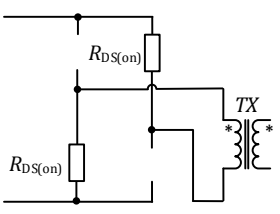

Fig. 5. Equivalent scheme of the inverter during the shoot-through (a) and the active (b) state.

MOSFETs conduction losses that corresponds to the shootthrough state is only two times higher than in IFBB converter. Impact of this component decreases as the shoot-through duty cycle decreases and thus inverter MOSFETs conduction losses are equal for both converters at unity step-up factor.

Switching losses consist of turn-on and turn-off losses:

$$
P_{M_{-} s w}=4 \cdot\left(P_{M_{-} o n}+P_{M_{-} o f f}\right),
$$

where $P_{M_{-} \text {on }}$ and $P_{M_{-} \text {off }}$ are the MOSFET turn-on and turn-off losses accordingly [19]:

$$
\begin{aligned}
P_{M_{-} \text {on }}=\frac{1}{2} \cdot \alpha & \cdot\left(I_{I N}-I_{I N} \cdot \Delta I_{\%} / 200\right) \cdot \frac{V_{\text {out }}}{2 n} \times \\
& \times\left(\frac{Q_{S W}}{V_{\text {drive }}} \cdot\left(R_{g}+R_{\text {drive }}\right)\right) \cdot f_{S W},
\end{aligned}
$$

where $I_{I N}$ is the converter input current, $Q_{S W}$ is the MOSFET switching charge, $V_{\text {drive }}$ is the MOSFET driver logical "high" voltage $(15 \mathrm{~V}), R_{g}$ is the MOSFET internal gate resistance, $R_{\text {drive }}$ is the MOSFET driver current limiting resistor (2 $\Omega$ );

$$
\begin{aligned}
P_{M_{-} \text {off }}=\frac{1}{2} \cdot \alpha & \cdot\left(I_{I N}+I_{I N} \cdot \Delta I_{\%} / 200\right) \cdot \frac{V_{\text {out }}}{2 n} \times \\
& \times\left(\frac{Q_{S W}}{V_{\text {drive }}} \cdot\left(R_{g}+R_{\text {drive }}\right)\right) \cdot f_{S W},
\end{aligned}
$$

In both equations (12)-(13) the coefficient $\alpha$ is used to take into account difference between MOSFET current in shootthrough state in the qZS and IFBB converters. In the worth case, when all switching transients are hard, the inverter MOSFET switching losses differs by two times, since $\alpha=0.5$ for IFBB converter and $\alpha=1$ for qZS converter. At constant input current, the switching losses of the inverter MOSFETs do not depend on the duty cycle and are fully determined by the parameters of the MOSFETs and the isolation transformer.

\section{B. VDR Losses} [20]

The conduction losses of VDR diodes could be estimated by

$$
P_{V D R_{-} c o n}=2 \cdot\left(V_{F V_{-} \text {Vrect }} \cdot \frac{P}{V_{\text {OUT }}}\right),
$$

where $V_{F V_{-} \text {Vrect }}$ is the forward voltage drop of the VDR diode.

As seen from (14), conduction losses are growing with the output power.

\section{Power Losses in the qZS Diode}

Since the diode is used in the qZS network, the conduction losses depend only on its average current [18], [19]:

$$
P_{D q Z S_{-} c o n}=V_{F V_{-} D q Z S} \cdot I_{I N},
$$

where $V_{F V_{-} D q Z S}$ is the forward voltage drop of the qZS diode.

Conduction losses of the qZS diode depend on the shootthrough duty cycle. Taking into account the change of $D_{S}$ in the range of $0 \ldots 0.25$ (for the converter operating with the twofold input voltage range), the conduction losses will change roughly only by $6 \%$.

\section{Losses in Clamping MOSFET}

Total power losses on the clamping switch consist of three components:

$$
P_{C L}=P_{C L_{-} \text {con }}+P_{C L_{-} \text {on }}+P_{C L_{-} \text {off }} \text {, }
$$

where $P_{C L_{-} \text {con }}$ is the clamping switch conduction losses, $P_{C L_{-} \text {on }}$ and $P_{C L_{-} \text {off }}$ are the clamping MOSFET turn-on and turn-off losses [11], [16]:

$$
\begin{aligned}
& P_{C L_{-} \text {con }}=\frac{R_{D S(\text { on })} \cdot I_{I N}^{2}}{2} \cdot\left(1-D_{S}\right) \text {, } \\
& P_{M_{-} \text {on }}=\frac{1}{2} \cdot\left(I_{I N}-I_{I N} \cdot \Delta I_{\%} / 200\right) \cdot \frac{V_{o u t}}{2 n} \times \\
& \times\left(\frac{Q_{S W}}{V_{\text {drive }}} \cdot\left(R_{g}+R_{\text {drive }}\right)\right) \cdot f_{S W} \\
& P_{M_{-} \text {off }}=\frac{1}{2} \cdot\left(I_{I N}+I_{I N} \cdot \Delta I_{\%} / 200\right) \cdot \frac{V_{o u t}}{2 n} \times \\
& \times\left(\frac{Q_{S W}}{V_{\text {drive }}} \cdot\left(R_{g}+R_{\text {drive }}\right)\right) \cdot f_{S W}
\end{aligned}
$$

Equations (17)-(19) indicate that only conduction losses depend on the shoot-through duty cycle. So, at constant input current, the total losses of the clamping switch will be growing, moving toward the unity step-up factor $\left(D_{S}=0\right)$.

\section{SiMULATION RESULTS}

The $300 \mathrm{~W}$ solar module-integrated converter (MIC) was selected as the case study for the modeling. Typically MICs working with a single PV-panel have the nominal output power in the range $240-275 \mathrm{~W}$ and maximum power point voltage near $30 \mathrm{~V}$ at standard test conditions. The converter parameters must be within that range. The simulation parameters of the converters are listed in Table I.

The power losses and efficiency of both converters were analyzed in four operating points, which cover the whole input voltage range (Table II). The operation parameters of each point were selected to achieve the maximum input current. As seen from Table II and (2), (3), the shoot-through duty cycle $D_{S}$ needed to achieve the desired voltage boost factor is two times smaller for the qZS converter as compared to the IFBB converter counterpart. This has considerable influence on the distribution of the losses in the converters.

The power loss was analyzed by means of the PSIM simulation software with Thermal Module. It enables the calculation of the power loss in the semiconductor elements based on their datasheet parameters. The semiconductor 
elements selected for the simulation and their main parameters are presented in Table III.

To compare simulation and theoretical results, the losses calculated using (9)-(19) are shown in Tables IV and V for qZS and IFBB converters, respectively. The IFBB converter shows up to $4.7 \%$ higher calculated efficiency in boost mode.

The simulation results are presented in Tables VI and VII for qZS and IFBB converters, respectively. Fig. 6 shows the graphical representation of the semiconductor losses for both topologies. The dependence of semiconductor losses on the

TABLE I

PARAMETERS OF THE COMPARED DC-DC CONVERTERS

\begin{tabular}{|l|c|c|}
\hline Parameter & Symbol & Value \\
\hline Input voltage range, $\mathrm{V}$ & $V_{I N}$ & $15 \ldots 30$ \\
\hline Maximum input current, A & $I_{I N}$ & 10 \\
\hline Output voltage, $\mathrm{V}$ & $V_{O U T}$ & 300 \\
\hline Switching frequency, $\mathrm{kHz}$ & $f_{S W}$ & 100 \\
\hline Transformer turns ratio & $n$ & 5 \\
\hline Capacitance of output capacitors, $\mathrm{uF}$ & $C_{1}, C_{2}$ & 2.2 \\
\hline Converters power rating, W & $P$ & 300 \\
\hline Peak-to-peak input current ripple, $\%$ & $\Delta I_{\%}$ & 10 \\
\hline Peak-to-peak voltages ripple, $\%$ & $\Delta V_{\%}$ & 1 \\
\hline Transformer magnetizing inductance, $\mathrm{uH}$ & $L_{T X_{-} m}$ & 60 \\
\hline Transformer primary leakage ind., $\mathrm{uH}$ & $L_{T X_{-} l e a k}$ & 0.38 \\
\hline \multicolumn{2}{|c|}{$\mathrm{qZS}$ converter } \\
\hline Capacitance of qZS capacitors, $\mathrm{uF}$ & $C_{\mathrm{qz} 1}, C_{\mathrm{qz} 2}$ & 33 \\
\hline Inductance of qZS inductors, $\mu \mathrm{H}$ & $L_{\mathrm{qz} 1}, L_{\mathrm{qz} 2}$ & 28 \\
\hline \multicolumn{2}{|c|}{$\mathrm{IFBB}$ converter } \\
\hline Inductance of boost inductor, $\mu \mathrm{H}$ & $L_{\mathrm{in}}$ & 38 \\
\hline Capacitance of clamping capacitor, uF & $C_{C L}$ & 17 \\
\hline
\end{tabular}

TABLE II

InPUt Voltage AND Power IN THE SELECTEd OPERATING PoINTS

\begin{tabular}{|l|c|c|c|c|}
\hline Operating point & $\mathbf{1}$ & $\mathbf{2}$ & $\mathbf{3}$ & $\mathbf{4}$ \\
\hline$V_{I N}, \mathrm{~V}$ & 15 & 20 & 25 & 30 \\
\hline$P, \mathrm{~W}$ & 150 & 200 & 250 & 300 \\
\hline$D_{S_{-} Z Z S}$ & 0.25 & 0.167 & 0.083 & 0 \\
\hline$D_{S_{I} I F B B B}$ & 0.5 & 0.333 & 0.167 & 0 \\
\hline
\end{tabular}

TABLE III

SEMICONDUCTOR COMPONENTS SELECTED FOR THE SimULATION

\begin{tabular}{|l|c|c|}
\hline Component & Type & Specifications \\
\hline \multirow{2}{*}{$S_{1} \ldots S_{4}, S_{C L}$} & Vishay & $V_{D S}=100 \mathrm{~V}, R_{D S(o n)}=8.8 \mathrm{~m} \Omega$, \\
& Si4190ADY & $\begin{array}{c}I_{D}=18.4 \mathrm{~A}, C_{O S S}=695 \mathrm{pF}, R_{g}=1.1 \Omega, \\
Q_{g}=67 \mathrm{nC}\end{array}$ \\
\hline$D$ & Vishay & $V_{R R M}=100 \mathrm{~V}, V_{F}=0.66 \mathrm{~V}$, \\
& V60D100C & $I_{F}=2 \times 30 \mathrm{~A}$ \\
\hline$D_{1}, D_{2}$ & CREE & $V_{R R M}=600 \mathrm{~V}, V_{F}=1.8 \mathrm{~V}, I_{F}=4 \mathrm{~A}$ \\
\hline
\end{tabular}

TABLE IV

CALCULATED POWER LOSSES OF THE QZS CONVERTER

\begin{tabular}{|l|c|c|c|c|}
\hline \multirow{2}{*}{} & \multicolumn{4}{|c|}{ Output power, W } \\
\cline { 2 - 5 } & 150 & 200 & 250 & 300 \\
\hline qZS diode (cond.), W & 6.60 & 6.60 & 6.60 & 6.60 \\
\hline MOSFETs (cond.), W & 1.47 & 1.63 & 1.92 & 2.35 \\
\hline MOSFETs (switch), W & 1.10 & 1.10 & 1.10 & 1.10 \\
\hline Rectifier diodes (cond.), W & 1.80 & 2.40 & 3.00 & 3.60 \\
\hline Total losses, W & 10.97 & 11.73 & 12.62 & 13.65 \\
\hline Efficiency, \% & 92.7 & 94.1 & 95.0 & 95.5 \\
\hline
\end{tabular}

TABLE V

CALCUlated POWER LOSSES OF THE IFBB CONVERTER

\begin{tabular}{|l|c|c|c|c|}
\hline \multirow{2}{*}{} & \multicolumn{4}{|c|}{ Output power, $\mathrm{W}$} \\
\cline { 2 - 5 } & 150 & 200 & 250 & 300 \\
\hline Clamping MOSFET, W & 0.50 & 0.57 & 0.64 & 0.72 \\
\hline MOSFETs (cond.), W & 1.03 & 1.34 & 1.78 & 2.35 \\
\hline MOSFETs (switch), W & 0.55 & 0.55 & 0.55 & 0.55 \\
\hline Rectifier diodes (cond.), W & 1.80 & 2.40 & 3.00 & 3.60 \\
\hline Total losses, W & 3.87 & 4.86 & 5.97 & 7.21 \\
\hline Efficiency, \% & 97.4 & 97.6 & 97.6 & 97.6 \\
\hline
\end{tabular}

output power for the qZS and IFBB converters are shown in Figs. 7 and 8, respectively. In both converters the contribution of switching losses of the MOSFETs to the total losses remains nearly the same for the whole operation range. The IFBB converter has lower switching losses due to the clamping network that brings inverter stage MOSFET operation mode to partial soft-switching at higher loads.

It is observed that in the qZS converters the main contributor of losses is the qZS diode. It generates more than $50 \%$ of the total losses in the entire operation range. As the power increases, the conduction losses on the qZS diode are decreasing due to the minimization of the input current ripple in the operating point with the unity step-up factor.

The second main source of losses in the qZS and the main one in the IFBB converter is the conduction losses of the VDR diodes. In both cases they are increasing almost linearly along with the output power increase. This is due to the increase of the output current while the rectifier diodes forward voltage drop remains nearly constant. In the point with the unity stepup factor, the VDR conduction losses are equal for both topologies as they are working with the same output current

TABLE VI

SIMULATED POWER LOSSES OF THE QZS CONVERTER

\begin{tabular}{|l|c|c|c|c|}
\hline \multirow{2}{*}{} & \multicolumn{4}{|c|}{ Output power, W } \\
\cline { 2 - 5 } & 150 & 200 & 250 & 300 \\
\hline qZS diode (cond.), W & 6.45 & 6.31 & 6.28 & 6.24 \\
\hline MOSFETs (cond.), W & 1.98 & 2.07 & 2.37 & 2.50 \\
\hline MOSFETs (switch), W & 0.39 & 0.39 & 0.37 & 0.49 \\
\hline Rectifier diodes (cond.), W & 1.39 & 1.99 & 2.60 & 3.30 \\
\hline Total losses, W & 10.21 & 10.76 & 11.62 & 12.53 \\
\hline Efficiency, \% & 93.2 & 94.6 & 95.4 & 95.8 \\
\hline
\end{tabular}

TABLE VII

SIMULATEd POWER LOSSES OF THE IFBB CONVERTER

\begin{tabular}{|l|c|c|c|c|}
\hline \multirow{2}{*}{} & \multicolumn{4}{|c|}{ Output power, W } \\
\cline { 2 - 5 } & 150 & 200 & 250 & 300 \\
\hline Clamping MOSFET, W & 0.41 & 0.44 & 0.48 & 0.52 \\
\hline MOSFETs (cond.), W & 1.70 & 1.94 & 2.22 & 2.49 \\
\hline MOSFETs (switch), W & 0.29 & 0.25 & 0.21 & 0.20 \\
\hline Rectifier diodes (cond.), W & 1.69 & 2.24 & 2.78 & 3.34 \\
\hline Total losses, W & 4.09 & 4.87 & 5.69 & 6.55 \\
\hline Efficiency, \% & 97.3 & 97.6 & 97.7 & 97.8 \\
\hline
\end{tabular}




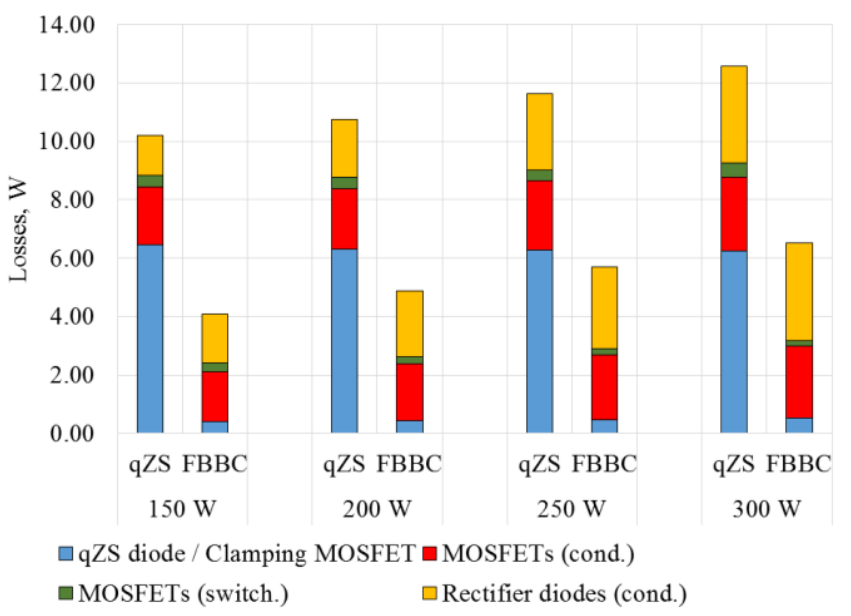

Fig. 6. Semiconductor power losses breakdown of the qZS and IFBB converters.

and duty cycle. At the same time, in other operating modes the VDR losses in the qZS topology are lower than in the IFBB topology. The reason is that to provide the same average output current with a lower active state duty cycle, the VDR diode peak current in the IFBB converter must be higher.

In the IFBB converter, the $D_{A}$ increases with the output power growing. Therefore, the losses in the clamping MOSFET are rising, since it is conducting only during the active state. In general, the direct impact of the clamping MOSFET losses on the converter efficiency is insignificant.
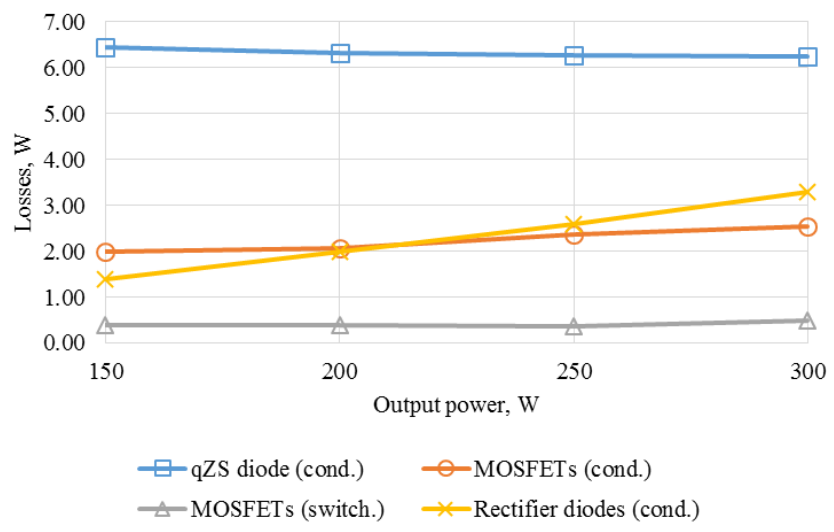

Fig. 7. Semiconductor power losses versus output power in the qZS converter.
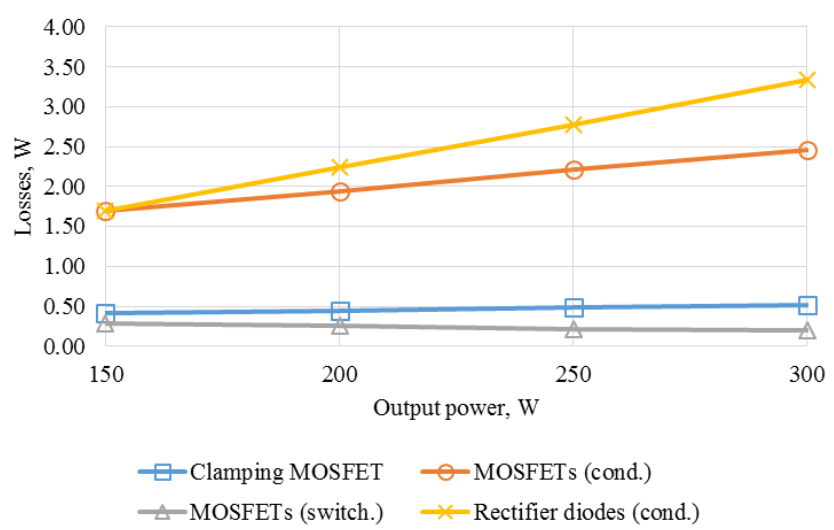

Fig. 8. Semiconductor power losses versus output power in the IFBB converter.

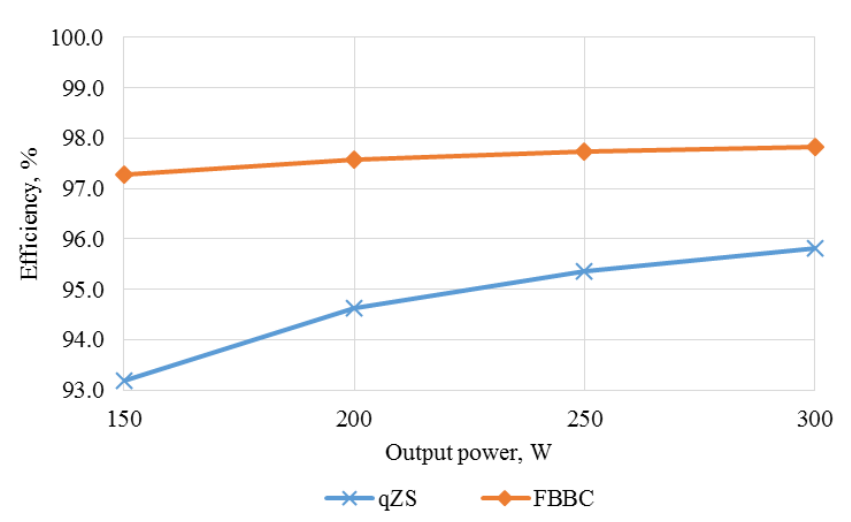

Fig. 9. Efficiency of qZS and IFBB converters versus output power.

Nevertheless, the clamping network has substantial impact on the inverter MOSFET switching losses [10], [15].

The switching losses of the inverter MOSFETs in qZS converter are higher than that in the IFBB converter. It is a result of the higher switching current in boost mode for qZS, as predicted by (12)-(13), and soft-switching possibilities of the IFBB converter with active clamping [24]. This softswitching performs better at higher load and leads to lower switching losses of the inverter MOSFETs.

The last component in the power losses is the MOSFET conduction losses. They are increasing with the output power increase due to the higher power losses during active state, which depend on the load. In the active state, two MOSFETs are connected in series with the transformer primary winding and conducting output current reflected to the primary winding of the isolation transformer. With given test conditions for both converter topologies the RMS current of the inverter MOSFETs during active state interval differs in boost mode. However they feature equal conduction losses in active state, since different in RMS currents is compensated by the difference of active state duty cycles. The difference in total conduction losses of the inverter MOSFETs for these two converters is determined by the losses during shoot-through state. As shown in Fig. 5, in the shoot-through state the input current is flowing through the parallel connection of two branches with two conducting MOSFETs connected in series [7]. For the IFBB converter in the shoot-through state, the RMS current through each inverter MOSFET is equal to half of the average input current. In the qZS converter the RMS MOSFET current equals to the average input current. Consequently, the conduction losses during shoot-through state in the inverter MOSFETs of the qZS converter are two times higher than that of the IFBB converter, taking into account two times higher duty cycle required for IFBB converter to achieve the same voltage step-up as in the qZS converter. In both converters the conduction losses during the shoot-through state are proportional to its duty cycle. Therefore their impact growing as the step-up factor increases, i.e. the converter input voltage decreases). Since the difference in the conduction losses between two converters is determined only by the component caused from the shoot-through state, the inverter MOSFETs conduction losses are equal for both 
topologies in the operating point with the unity step-up factor, which was confirmed by the simulation.

The dependences of the efficiency on the output power for both converters are summarized in Fig. 9. As can be seen, the efficiency curve of the IFBB converter is flat over the whole operation range, while the qZS converter efficiency drops significantly with the decrease of the output power. This efficiency drop is caused mainly by the nearly constant qZS diode conduction losses. They have a crucial impact on the efficiency at light loads.

In general, the distribution of the losses and their dependence on the output power corresponds to the analytical expressions in section III of this paper.

\section{CONCLUSION}

In this paper the semiconductor losses in the isolated qZS and IFBB converters were analyzed and compared.

The comparison shows that the IFBB DC-DC converter topology could be more preferable in low-voltage applications than the conventional qZS full-bridge converter topology with a diode in the qZS network. At the same time, the IFBB converter topology has a number of drawbacks that limit its use. Major drawbacks are the high inrush current and higher voltage stresses under hard-switching as compared to the qZS and conventional voltage fed topologies. Additional active clamping circuit is commonly used in the IFBB converters to improve their switching performance.

Nevertheless, both topologies can be significantly improved in terms of efficiency. For example, by accommodating synchronous qZS-network and synchronous rectification it is possible to increase the maximum efficiency of the qZS converter by up to $3 \%$ [7]. This eliminates the main drawback of the qZS converter in low voltage applications. By accommodating separated commutation and four quadrant active switches to the IFBB converter, it is possible to limit voltage stress by achieving full soft-switching and to minimize rectifier stage conduction losses by the use of synchronous rectification [4], [20].

Efficiency is not a single factor in topology selection for low voltage applications. The following additional points for consideration have resulted from our comparison of the discussed topologies in terms of practical applications:

1) qZS converters need fewer MOSFETs, which provides cost savings on MOSFETs themselves, driver circuits, and control system.

2) IFBB converters have only one energy-accumulating inductor as compared to two inductors in the qZS topology. At the same time, the inductance of the IFBB converter inductor is higher than the inductance of the qZS inductors. Moreover, the qZS network inductors can be magnetically coupled, which allows the required inductance value to be reduced two times in the same operating conditions [13], [21]. It means that the qZS can be implemented with a single magnetic component like the IFBB converter.

3) qZS DC-DC converters can work in both the shootthrough and the open state of the inverter, while the
IFBB converter needs special circuits and more complex control algorithms to protect the inverter from the voltage overshoot caused by the boost inductor if the open state occurs in the inverter bridge.

4) qZS DC-DC converters have comparatively low efficiency in low voltage applications but can additionally operate in the buck mode (without any additional switches), providing a wider operation range without any need for clamping circuits to protect switches from the voltage stress.

5) qZS DC-DC converters have higher step-up factor (up to 3 with an acceptable level of MOSFET conduction losses), which extends the operating range as compared to that of the IFBB converter [7].

By adopting modern control algorithms and semiconductor devices, current fed topologies have all chances to become widespread in low voltage applications, especially those requiring continuous input current. The choice of a particular topology is determined by the specific application and the additional requirements to the converter.

\section{ACKNOWLEDGMENT}

This study was co-financed by Estonian Ministry of Education and Research (project SF0140016s11) and Estonian Research Council (grant PUT744).

\section{REFERENCES}

[1] C. Qiao and K. M. Smedley, "An isolated full bridge boost converter with active soft switching," in IEEE 32nd Annu. Power Electron. Specialists Conf., PESC. 2001, vol. 2, 2001, pp. 896-903.

[2] R. Watson and F. C. Lee, "A soft-switched, full-bridge boost converter employing an active-clamp circuit," in 27th Annual IEEE Power Electronics Specialists Conf., PESC '96, vol. 2, 23-27 June 1996, pp. 1948-1954.

[3] A. Mousavi, P. Das and G. Moschopoulos, "A Comparative Study of a New ZCS DC-DC Full-Bridge Boost Converter With a ZVS ActiveClamp Converter," IEEE Trans. Power Electron., vol. 27, no. 3, pp. 13471358, March 2012. http://dx.doi.org/10.1109/TPEL.2011.2118233

[4] A. Blinov, D. Vinnikov and V. Ivakhno, "Full soft-switching high step-up dc-dc converter for photovoltaic applications," in 16th European Conf. Power Electron. and Appl., EPE'14-ECCE Europe, Aug. 2014, pp. 1-7.

[5] E. S. Park, S. J. Choi, J. M. Lee and B. H. Cho, "A soft-switching activeclamp scheme for isolated full-bridge boost converter," in 19th Annu. IEEE Appl. Power Electron. Conf. and Exposition, APEC '04, vol. 2, 2004, pp. 1067-1070.

[6] D. Vinnikov et al., "Performance improvement method for the voltagefed qZSI with continuous input current," in 15th IEEE Mediterranean Electrotechnical Conf., MELECON 2010, 26-28 April 2010, pp. 14591464 .

[7] L. Liivik, D. Vinnikov and J. Zakis, "Simulation study of high step-up quasi-Z-source DC-DC converter with synchronous rectification," in 55th Int. Scientific Conf. Power and Electrical Engineering of Riga Technical University, RTUCON 2014, 14 Oct. 2014, pp. 34-37.

[8] D. Vinnikov and I. Roasto, "Quasi-Z-Source-Based Isolated DC/DC Converters for Distributed Power Generation," IEEE Trans. Ind. Electron., vol. 58, no. 1, Jan. 2011, pp. 192-201. http://dx.doi.org/10.1109/TIE.2009.2039460

[9] Y. Li et al., "Quasi-Z-Source Inverter for Photovoltaic Power Generation Systems," in 24th Annu. IEEE Applied Power Electron. Conf. and Exposition, APEC 2009, 15-19 Feb. 2009, pp. 918-924. http://dx.doi.org/10.1109/APEC.2009.4802772

[10] J. Zakis et al., "New active clamp circuit for current-fed galvanically isolated DC/DC converters," in 8th Int. Conf. on Compatibility and Power Electron., CPE 2013, 5-7 June 2013, pp. 353-358.

[11] J. Zakis, D. Vinnikov and I. Rankis, "Steady state analysis of the galvanically isolated DC/DC converter with a commutating LC filter," in 
IEEE Int. Conf. on Industrial Technology, ICIT 2012, 19-21 March 2012 , pp. 827-832. http://dx.doi.org/10.1109/ICIT.2012.6210041

[12] A. K. Rathore and X. Li, "Comparison of zero-voltage-switching current-fed full-bridge and half-bridge isolated Dc/Dc converters with active-clamp," in IEEE 9th Int. Conf. Power Electron. and Drive Systems, PEDS 2011, 5-8 Dec. 2011, pp. 133-138 http://dx.doi.org/10.1109/PEDS.2011.6147236

[13] D. Vinnikov et al., "New step-up DC/DC converter for fuel cell powered distributed generation systems: Some Design Guidelines," Przeglad Elektrotechniczny, vol. 86, 2010, pp. 245-252.

[14] L. Zhu et al., "New start-up schemes for isolated full-bridge boost converters," in 15th Annu. IEEE Applied Power Electron. Conf. and Exposition, APEC 2000, vol. 1, 2000, pp. 309-313.

[15] R. Pittini, Z. Zhang, and M. A. E. Andersen, "Isolated full bridge boost DC-DC converter designed for bidirectional operation of fue cells/electrolyzer cells in grid-tie applications," in 15th European Conf. Power Electron. and Applications, EPE 2013, 2-6 Sept. 2013, pp. 1-10.

[16] N. Mohan, T. Undeland and W. Robbins, Power Electronics: Converters, Applications, and Design, 3rd ed., Wiley, 2002.

[17] R. Erickson and D. Maksimovic, Fundamentals of Power Electronics, Springer Science \& Business Media, 2001 http://dx.doi.org/10.1007/b100747

[18] L. Liivik, D. Vinnikov and T. Jalakas, "Synchronous Rectification in Quasi-Z-Source Converters: Possibilities and Challenges," in IEEE Int. Conf. Intelligent Energy and Power Systems, IEPS 2014, Kyiv, Ukraine, June 2-6, 2014. http://dx.doi.org/10.1109/ieps.2014.6874196

[19] D. Vinnikov, O. Husev and I. Roasto, "Lossless Dynamic Models of the Quasi-Z-Source Converter Family," Scientific J. of Riga Technical University. Power and Electrical Engineering, vol. 29, 2011, pp. 73-78.

[20] R. Kosenko, O. Husev, and A. Chub, "Full soft-switching high step-up current-fed DC-DC converters with reduced conduction losses," in 5th Int. Conf. Power Engineering, Energy and Electrical Drives, POWERENG 2015, 2015, submitted for publication.

[21] J. Zakis, et al., "Practical Design Guidelines of qZSI Based Step-Up DC/DC Converter," Scientific J. of Riga Technical University. Power and Electrical Engineering, vol. 27, 2010, pp. 108-115.

[22] S. Kouro, et al., "Grid-Connected Photovoltaic Systems: An Overview of Recent Research and Emerging PV Converter Technology," IEEE Ind. Electronics Magazine, vol. 9 no. 1, 2015, pp. 47-61. http://dx.doi.org/10.1109/MIE.2014.2376976

[23] D. Vinnikov and I. Roasto, "Quasi-Z-Source-Based Isolated DC/DC Converters for Distributed Power Generation," IEEE Trans. Ind. Electronics, vol. 58, no. 1, 2011, pp. 192-201. http://dx.doi.org/10.1109/TIE.2009.2039460

[24] U. R. Prasanna and A. K. Rathore, "Extended Range ZVS ActiveClamped Current-Fed Full-Bridge Isolated DC/DC Converter for Fuel Cell Applications: Analysis, Design, and Experimental Results," IEEE Trans. Ind. Electronics, vol. 60, no. 7, 2013, pp. 2661-2672. http://dx.doi.org/10.1109/TIE.2012.2194977

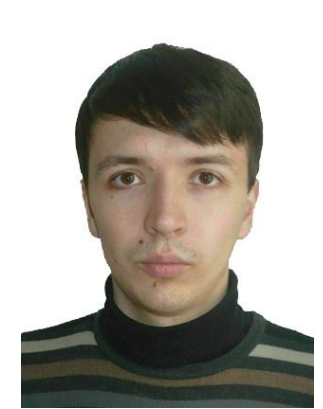

Roman Kosenko received Dipl.-Eng. and M. Sc. in Electronics from the Department of Industrial Electronics, Chernihiv State University of Technology, Chernihiv, Ukraine, in 2011 and 2013, respectively. He is currently working toward the $\mathrm{Ph} . \mathrm{D}$. degree at the Department of Electrical Engineering of Tallinn University of Technology and at the Biomedical Radioelectronic Apparatus and Systems Department of Chernihiv National University of Technology.

His fields of interest include research, design and simulation of switch mode converters for distributed power generation systems. He is author or co-author of 4 scientific papers and is the holder of one Utility Model.

Postal address: Department of Electrical Engineering, Tallinn University of Technology, Ehitajate tee 5, 19086 Tallinn, Estonia;

E-mail: mr.roman.kosenko@ieee.org

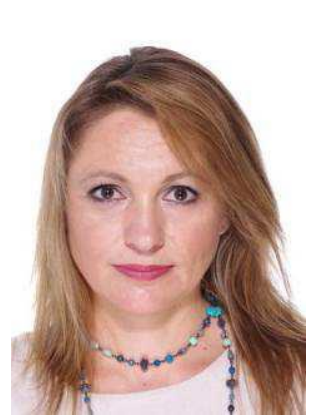

Liisa Liivik received Dipl.-Eng, M. Sc. in Electrical Engineering degrees from the Department of Electrical Drives and Power Electronics, Tallinn University of Technology, Tallinn, Estonia, in 1998 and 2000, respectively. She is currently working toward her Ph.D. degree at the Department of Electrical Engineering.

From 2002 to 2007, she was a lecturer in the Department of Electrical Drives and Power Electronics, Tallinn University of Technology. Her teaching areas included basics of measurement engineering and numerical calculations in electrical engineering. Her fields of interest are: research, design and simulation of switch mode converters for distributed power generation systems.

She received an award (2nd place) for her master thesis "Numerical Calculations of Electrotechnics" from Estonian Academy of Sciences and is author or co-author of more than 15 scientific papers and 1 book.

Postal address: Department of Electrical Engineering, Tallinn University of Technology, Ehitajate tee 5, 19086 Tallinn, Estonia;

E-mail: liisa.liivik@gmail.com

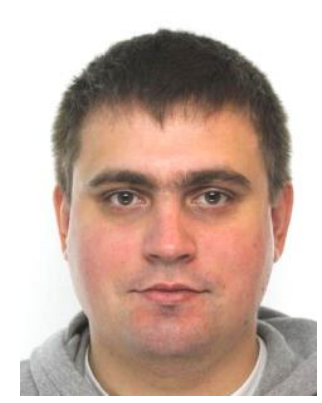

Andrii Chub received the B. Sc. degree in Electronics and M. Sc. degree in Electronic Systems from Chernihiv State Technological University, Chernihiv, Ukraine, in 2008 and 2009 respectively. He is currently pursuing the $\mathrm{Ph}$. D. degree in the Power Electronics Research Group, Tallinn University of Technology. He is employed as a Junior Researcher at the Department of Electrical Engineering, Tallinn University of Technology. He has co-authored more than 15 papers on power electronics and applications. His research interests include dc-dc converters, dc-ac inverters, impedance source electric energy conversion technology, implementation of the new wide bandgap semiconductors in power converters, and control of the renewable energy conversion systems.

Postal address: Department of Electrical Engineering, Tallinn University of Technology, Ehitajate tee 5, 19086 Tallinn, Estonia;

E-mail: andrii.chub@ieee.org

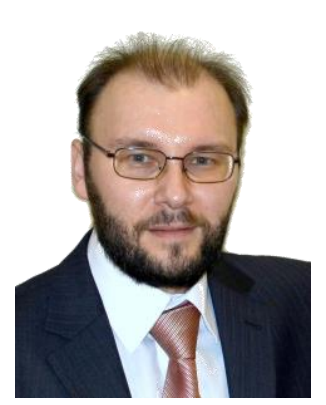

Oleksandr Velihorskyi received the B. Sc. and M. Sc. degrees in electronic systems from Chernihiv State University of Technology, Chernihiv, Ukraine, in 2001 and 2002, respectively. He received doctoral degree in semiconductor power converters from National Academy of Sciences, Institute of Electrodynamics, Kiev, Ukraine in 2007.

$\mathrm{He}$ is currently Head of Biomedical Radioelectronic Apparatus and Systems Department, Chernihiv National University of Technology. He has authored more than 20 published papers on power converters and is the holder of several Utility Models. His research interests include semiconductor power converters, photovoltaic, biomedical electronics.

Postal address: Chernihiv National University of Technology, Biomedical Radioelectronic Apparatus and Systems Department. Address: Shevchenko Str., 95, 14027, Chernihiv, Ukraine;

E-mail: oleksandr.veligorsky@inel.stu.cn.ua 